\title{
Perancangan Sistem Peminjaman Sound System Berbasis Web Pada Kantor Camat Rendang
}

\author{
Web-based Sound System Loaning System Design \\ at Rendang Subdistrict Office \\ I Gusti Ayu Desi Saryanti ${ }^{1}$, I Kadek Wijanegara ${ }^{2}$ \\ ${ }_{1,2}$ Sistem Informasi, STIKOM Bali \\ E-mail: ${ }^{1}$ desi@stikom-bali.ac.id, ${ }^{2}$ juan_tole@yahoo.com
}

\begin{abstract}
Abstrak
Teknologi sistem informasi seperti web adalah solusi untuk menghadapi sistem yang masih manual. Salah satu yang paling berpengaruh saat ini adalah Aplikasi Web atau yang sering disebut dengan Website. Kebutuhan suatu Website sudah sangat penting bagi setiap instansi atau suatu perusahaan baik itu swasta ataupun pemerintahan. Kantor Camat Rendang merupakan salah satu instansi yang memiliki jumlah pengolahan informasi yang cukup tinggi. Mulai dari pengolahan informasi pegawai sampai dengan pelayanan akan kebutuhan informasi pada masyarakat khususnya Kecamatan Rendang. Namun pelayanan terhadap masyarakat di Kantor Camat Rendang masih ada beberapa yang menggunakan sistem manual, seperti sistem peminjaman sound. Peminjaman sound sistem di Kantor Camat Rendang masih menggunakan cara manual yaitu peminjam langsung menghubungi lewat telepon. Namun sangat sering terjadi masalah dengan cara tersebut, khususnya dalam penentuan jadwal peminjaman. Hal ini tentunya dikarenakan terjadinya kesalahan dalam komunikasi antara peminjam dengan Pihak dari Kantor Camat Rendang. Untuk itu dibangulah suatu perancangan sistem peminjaman sound sistem menggunakan Data Flow Diagram untuk mempermudah karyawan dalam pengelolaan data sehingga menjadi lebih mudah, efektif dan efisien.
\end{abstract}

Kata Kunci - Web, Perancangan, Data Flow Diagram

\begin{abstract}
Technology information systems such as the web is the solution to confront the system that are still manual. One of the most influential today is a Web application or who is often called the Website. Needs a Website is very important for any agency or a private company or a government either. Rendang Head Office is one agency that has a number of information processing that is high enough. Start of processing employee information to the service will need information on a particular community Rendang district. But service to the community in the District Office Rendang there are still some who use manual systems, such as loan system sound. Loan sound system in Head Office Rendnag still use manual way that the borrower immediately contacted by telephone. But very often there are problems with the way, especially in the determination of the borrowing schedule. This is certainly due to the occurrence of an error in the communication between the borrower and the Persons of the District Office Rendang. For that dibangulah a sound borrowing system design systems using Data Flow Diagram to facilitate employees in the management of the data so that it becomes easier, effective and efficient.
\end{abstract}

Keywords: Web, Design, Data Flow Diagram 


\section{PENDAHULUAN}

Kemajuan ilmu pengetahuan dan teknologi terus berkembang dengan pesat, terutama pada bidang teknologi informasi atau information technology (IT). Salah satu dampak dari perkembangan teknologi informasi antara lain: pekerjaan yang mulanya masih menggunakan sistem manual mulai dikurangi dan pemanfaatan teknologi komputerisasi mulai ditingkatkan. Kecenderungan ini tampak dengan mulai digunakannya komputer, dimana komputer merupakan salah satu pendukung dari perkembangan teknologi informasi. Dengan menggunakan suatu sistem informasi yang baik, maka pengguna (users) akan mendapatkan kemudahan dalam melakukan pekerjaannya. Salah satu yang paling berpengaruh saat ini adalah Aplikasi Web atau yang sering disebut dengan Website.

Website atau lazim disingkat web adalah halaman informasi yang disediakan melalui jalur internet sehingga bisa diakses di seluruh dunia selama terkoneksi dengan jaringan internet. Apapun bahasanya, yang pasti kita semua setuju bahwa website merupakan kumpulan halaman yang menampilkan informasi data teks, data gambar diam atau gerak, data animasi, suara, video dan atau gabungan dari semuanya, baik yang bersifat statis maupun dinamis yang membentuk satu rangkaian bangunan yang saling terkait dimana masing-masing dihubungkan dengan jaringan-jaringan halaman (hyperlink).

Sehingga disimpulkan bahwa pada jaman sekarang ini, kebutuhan suatu Web Site sudah sangat penting bagi setiap instansi atau suatu perusahaan baik itu swasta ataupun pemerintahan. Karena Web Site sangat berpengaruh dalam memberikan suatu informasi kepada masyarakat luas yang sangat membutuhkan informasi yang serba cepat dan praktis pada era teknologi informasi sekarang ini.

Kantor Camat Rendang merupakan salah satu instansi negeri yang memiliki jumlah pengolahan informasi yang cukup tinggi. Mulai dari pengolahan informasi pegawaisampai dengan pelayanan akan kebutuhan informasi pada masyarakat khususnya Kecamatan Rendang. Namun pelayanan terhadap masyarakat Kantor Camat Rendang masih ada beberapa yang menggunakan sistem manual, seperti contoh Sistem Peminjaman Sound. Peminjaman sound di Kantor Camat Rendang masih menggunakan cara manual yaitu peminjam langsung menghubungi lewat telepon. Namun sangat sering terjadi masalah dengan cara tersebut, khususnya dalam penentuan jadwal peminjaman. Hal ini tentunya dikarenakan terjadinya kesalahan dalam komunikasi antara peminjam dengan Pihak dari Camat Rendang.

Berdasarkan uraian sebelumnya, menarik untuk di bangun sebuah perancangan sistem peminjaman Sound System berbasis web Kantor Camat Rendang, sehingga diharapkan dengan adanya sistem peminjaman sound system berbasis web ini dapat mempermudah dalam melakukan peminjaman Sound System. Untuk itu penulis tertarik untuk mengangkat judul "Perancangan Sistem Peminjaman Sound System Berbasis Web pada Kantor Camat Rendang“. 


\section{METODE PENELITIAN}

\subsection{Metode Pengumpulan Data}

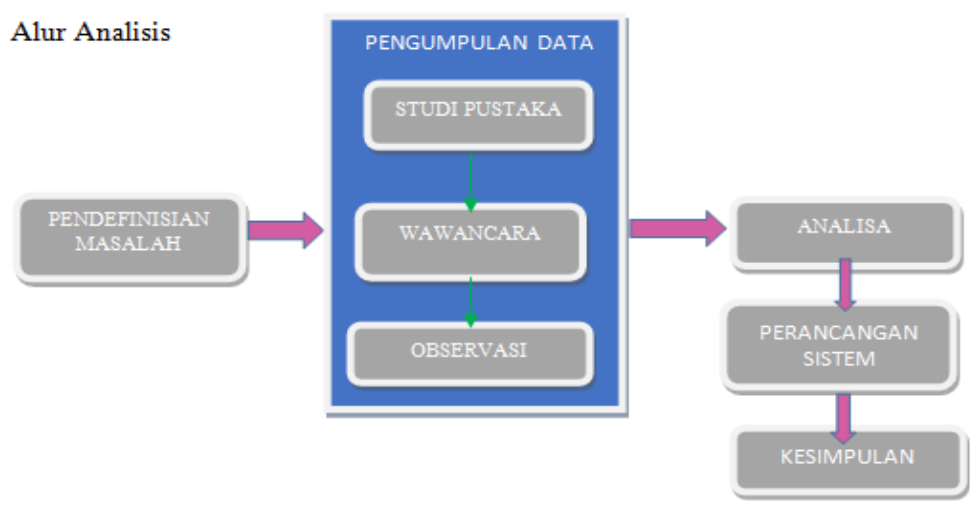

Gambar 1. Alur Analisis

Penelitian ini diawali dengan pengumpulan data dan dilanjutkan dengan penerapan dari metode yang digunakan. Tahapan kegiatan penelitian dapat dilihat pada Gambar 1, secara rinci dijabarkan sebagai berikut:

1. Pendefinisian permasalahan berkaitan dengan perancangan sistem

2. Studi Pustaka, pengumpulan data berupa buku-buku, paper atau dokumentasi yang berkaitan dengan penelitian yang dilakukan

3. Wawancara, dilakukan proses tanya jawab antara peneliti dengan responden

4. Observasi, yaitu pengamatan secara langsung pada proses-proses yang sedang berjalan

5. Analisa, melakukan proses penganalisaan terhadap permasalahan yang dibahas pada penelitian

6. Perancangan system, dilakukan dengan melakukan perancangan terhadap peminjaman sound system

7. Pengambilan kesimpulan

\subsection{Sistem}

Sistem adalah suatu jaringan kerja dari prosedur- prosedur yang saling berhubungan, berkumpul bersama-sama untuk melakukan suatu kegiatan atau untuk menyelesaikan suatu sasaran tertentu. [1]

\subsection{Sound System}

Sound system menurut (Gary Davis \& Ralph Jones) adalah susunan komponen elektronik yang dirancang sedemikian rupa untuk meningkatkan kekuatan suara, agar suara dapat didengar dengan jelas oleh banyak orang pada pertunjukan music, seminar dll. [2]

\subsection{Information Oriented Flowchart}

Menurut Jeffrey L. Whitten (1986:93), "Information Oriented Flow Chart adalah suatu system klasik yang menyatakan mengenai system aliran data yang lebih menekankan pada aliran system informasi mulai dari awal sampai dengan akhir sebuah sistem". Dari definisi di atas, Information Oriented Flow Chart dapat didefinisikan sebagai suatu sistem yang menggambarkan aliran data sehingga dapat diketahui informasi apa saja yang mengalir dalam suatu system kerja secara urut dari awal sampai akhir. [3] 


\subsection{Data Flow Diagram (DFD)}

Menurut Leman (1998) Data Flow Diagram adalah "Suatu gambaran yang menjelaskan bagaimana menggambarkan atau membuat model komponen sistem".Menurut Alton R. Kindred (1985:87), Data Flow Diagram adalah "Suatu gambaran tentang aliran data yang melewati suatu system dan beberapa proses yang bertujuan untuk mengubah bentuk data-data. Dari beberapa definisi di atas, maka dapat disimpulkan Data Flow Diagram adalah suatu metode yang digunakan untuk menggambarkan atau membuat suatu model dari input, output serta proses transformasinya pada suatu system sehingga system tersebut mudah dipahami. [4]

\subsection{Entity Relationship Diagram (ERD)}

Mendesain database merupakan suatu hal yang sangat penting. Kita menggunakan ERD untuk mendesainnya. ERD (Entity Relationship Diagram) ialah sebuah pemodelan untuk mendesain database yang baik. Karena tanpa ERD ini bias dipastikan proses pembuatan database berjalan lama dan tidak teratur. Pada saat mendesain database yang harus diperhatikan adalah membuat relasi-relasi yang benar diantara tabel. Proses desain database cukup menghabiskan waktu yang lama jika databasenya besar. Pendokumentasian desain database mutlak harus dilakukan dengan baik agar mudah di dalam pengembangan atau perbaikan nantinya. Pada pemodelan ERD, obyek dasar yang ada di dunia nyata diwakili oleh suatu entity. Dimana setiap entity memiliki sifat-sifat tertentu yang disebut attribute seperti Nama, Jenis Kelamin, dan Alamat. Entity digambarkan sebagai suatu belah ketupat dan atribut digambarkan sebagai persegi panjang. [4]

\section{HASIL DAN PEMBAHASAN}

\subsection{Deskripsi Sistem}

Sistem informasi merupakan suatu kerangka yang terdiri dari sumber-sumber daya yang terkoordinasi, mengumpulkan, memproses, mengendalikan, dan manajemen data melalui tahapan yang berurutan guna menghasilkan informasi yang akan disampaikan kepada berbagai pemakai untuk berbagai keperluan.

\subsection{Analisa dan Desain Sistem}

\subsubsection{Flowchart}

\subsubsection{Super Admin}

Merupakan Flowchart untuk Super Admin, di mulai dari Super Admin melakukan Login sebagai Super Admin, jika Login berhasil selanjutnya Super Admin akan melakukan maintenance. Maintenance ini ada 3 bagian yaitu: Maintenance data Admin, Maintenance data User dan Maintenance data Peminjaman Sound System. Setelah itu maka data akan disimpan. Proses tersebut terlihat pada Gambar 2. 


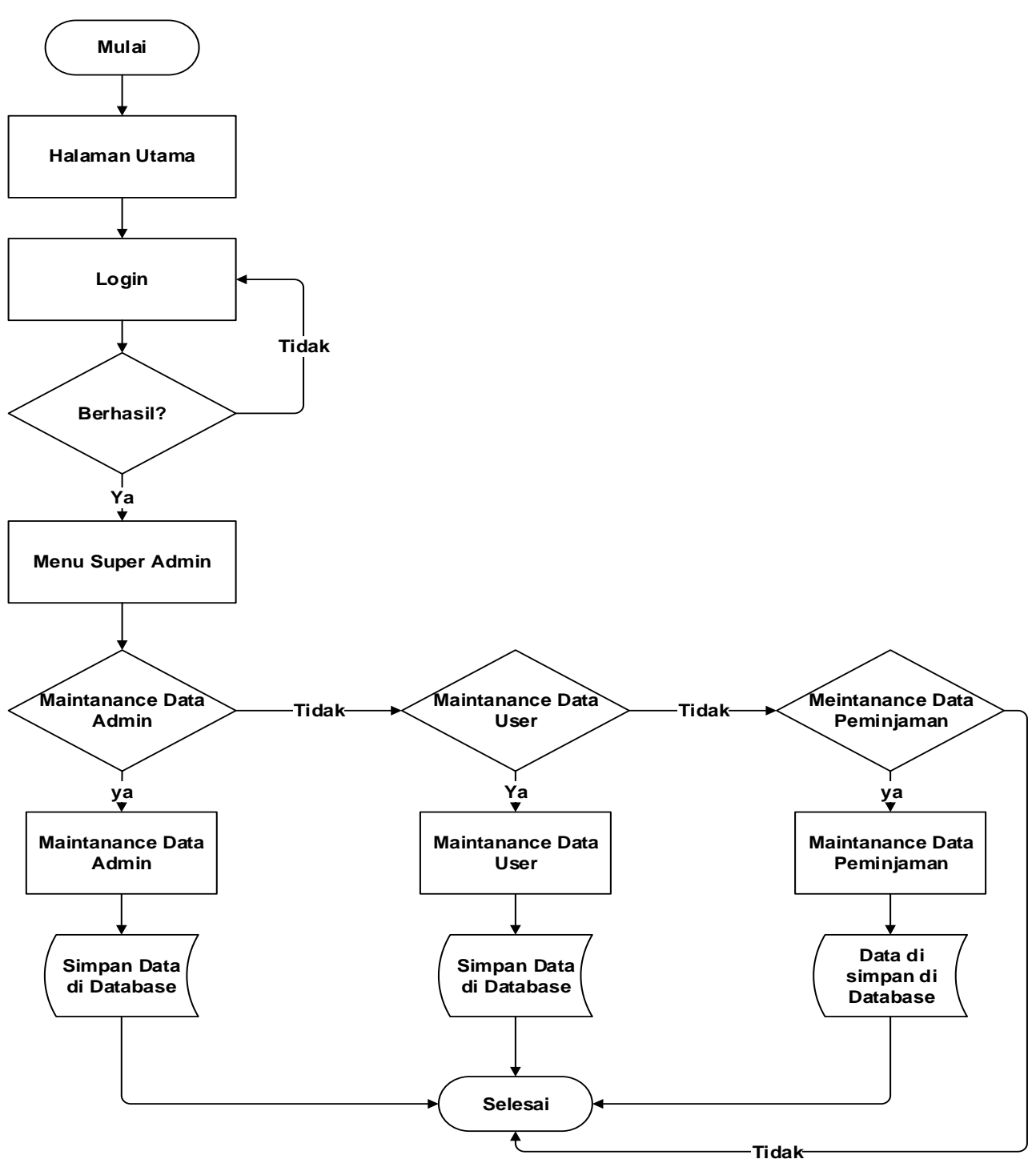

Gambar 2. Flowchart Super Admin 
Citec Journal, Vol. 3, No. 4, Agustus 2016 - Oktober 2016

\subsubsection{Admin}

Merupakan Flowchart untuk Admin. Di mulai dari Admin melakukan login. Jika login berhasil maka akan tampil menu admin. Disini admin hanya dapat melakukan maintenance Data Peminjaman. Lalu data tersebut akan disimpan. Proses tersebut terlihat pada Gambar 3.

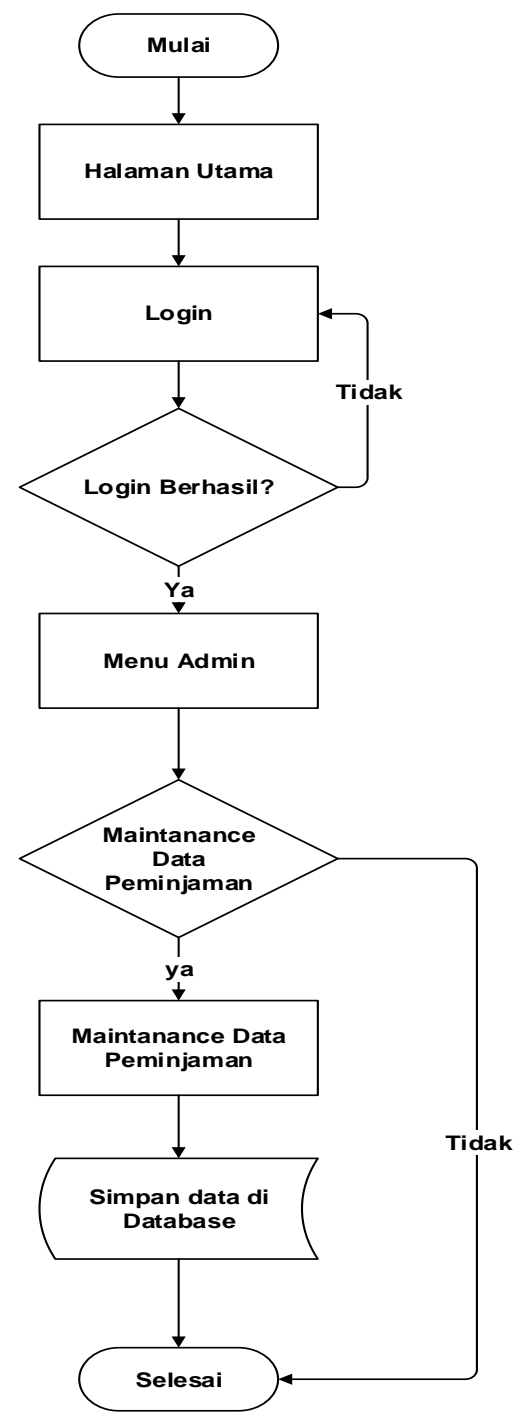

Gambar 3. Flowchart Admin 


\subsubsection{User}

Merupakan Flowchart Peminjaman Sound System, di mulai dari peminjam melakukan Login. Setelah login berhasil, maka akan muncul tampilan halaman peminjaman. Selanjutnya peminjam akan Mengisi form peminjaman. Lalu data tersebut akan disimpan ke database. Proses tersebut terlihat pada Gambar 4.

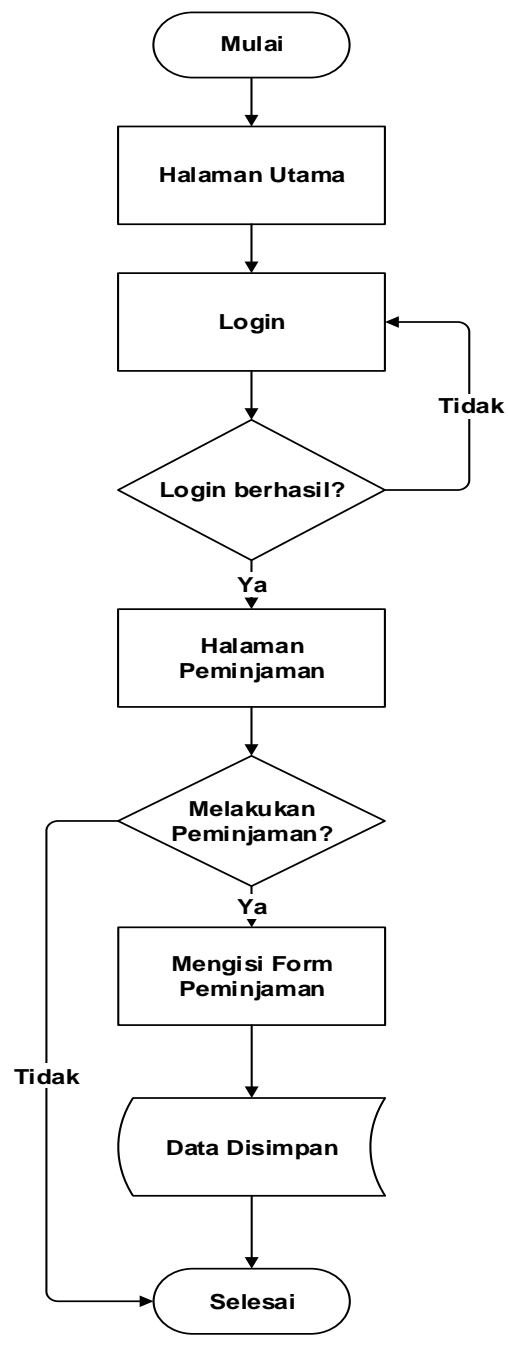

Gambar 4. Flowchart User

\subsubsection{Diagram Konteks}

Diagram konteks merupakan gambaran paling umum dari sebuah rancangan sistem. Diagram konteks hanya menggambarkan input-output dari sistem yang akan dibuat. Dalam diagram konteks yang terdapat pada Gambar 5, menggambarkan struktur dasar dari Sistem Peminjaman Sound System di Dinas Komunikasi dan Informatika Kota Denpasar yang akan dirancang. Sistem ini melibatkan 3 (tiga) external entity yaitu Super Admin, Admin dan User (Peminjam). 
Citec Journal, Vol. 3, No. 4, Agustus 2016 - Oktober 2016

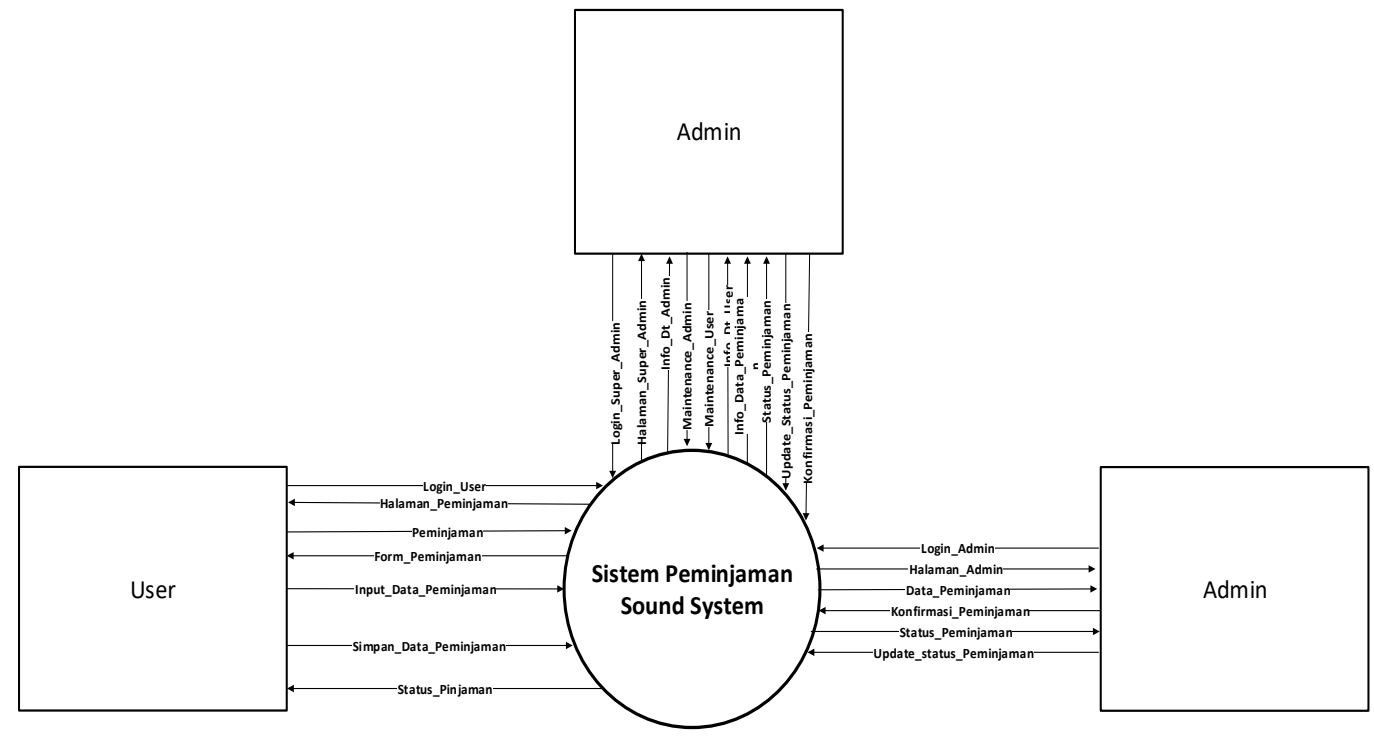

Gambar 5. Diagram Konteks

\subsubsection{Data Flow Diagram (DFD) level 0}

DFD level 0 ditunjukkan pada Gambar 6. Pada tahapan ini terdapat 3 (tiga) proses yang dapat dilakukan, yaitu proses Tambah Data, Login dan Peminjaman. Proses-proses tersebut dilakukan oleh 3(tiga) external entity yaitu Super admin, Admin dan User (Peminjam).

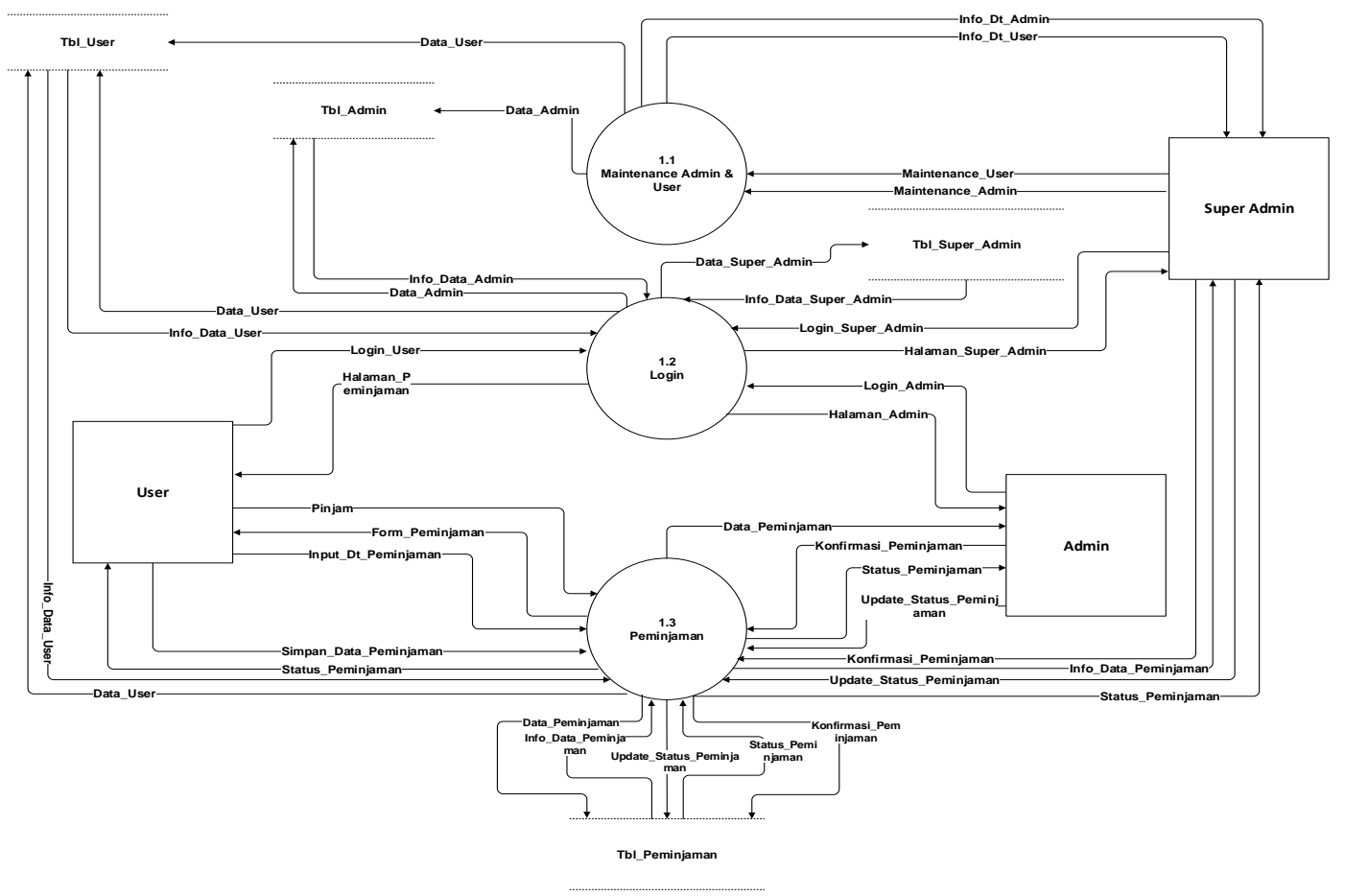

Gambar 6. Data Flow Diagram (DFD) level 0 


\subsubsection{Data Flow Diagram (DFD) level 1 Maintenance Admin \& User}

Gambar 7 merupakan Data Flow Diagram (DFD) level 1 Tambah Data, dimana proses Tambah Data di pecah menjadi 2 (dua) yaitu Proses Tambah data Admin dan proses Tambah data User.

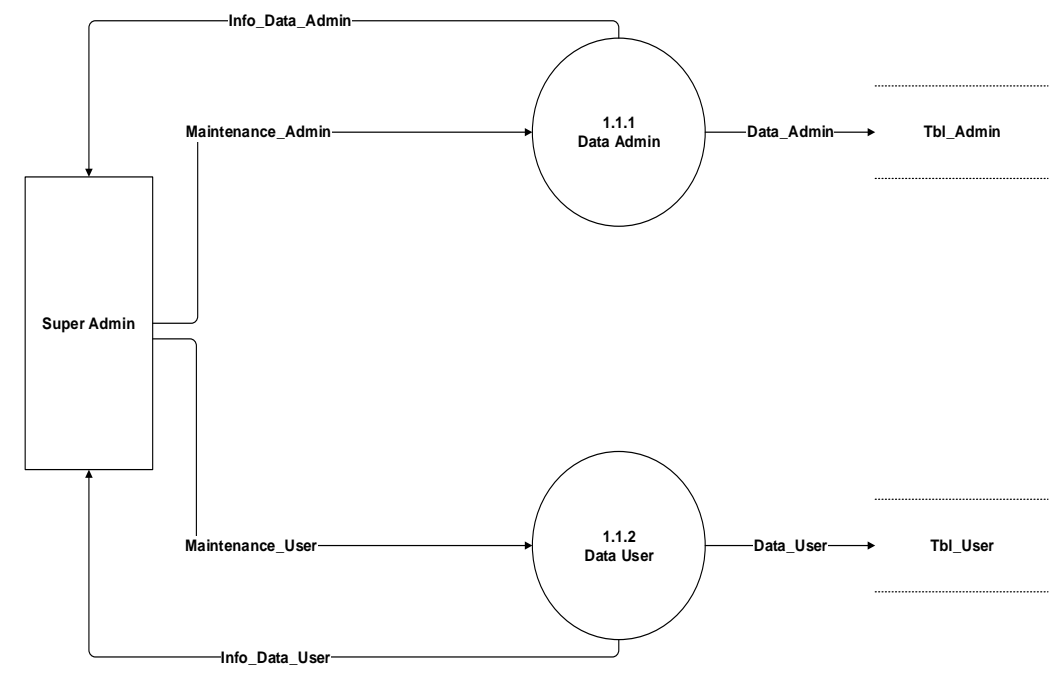

Gambar 7. Data Flow Diagram (DFD) level 1 Tambah Data

\subsubsection{Data Flow Diagram (DFD) level 1 Login}

Gambar 8 merupakan Data Flow Diagram (DFD) level 1 Login. Dimana proses Login di pecah menjadi 3 (tiga) yaitu Login Super Admin, Login Admin dan Login User.
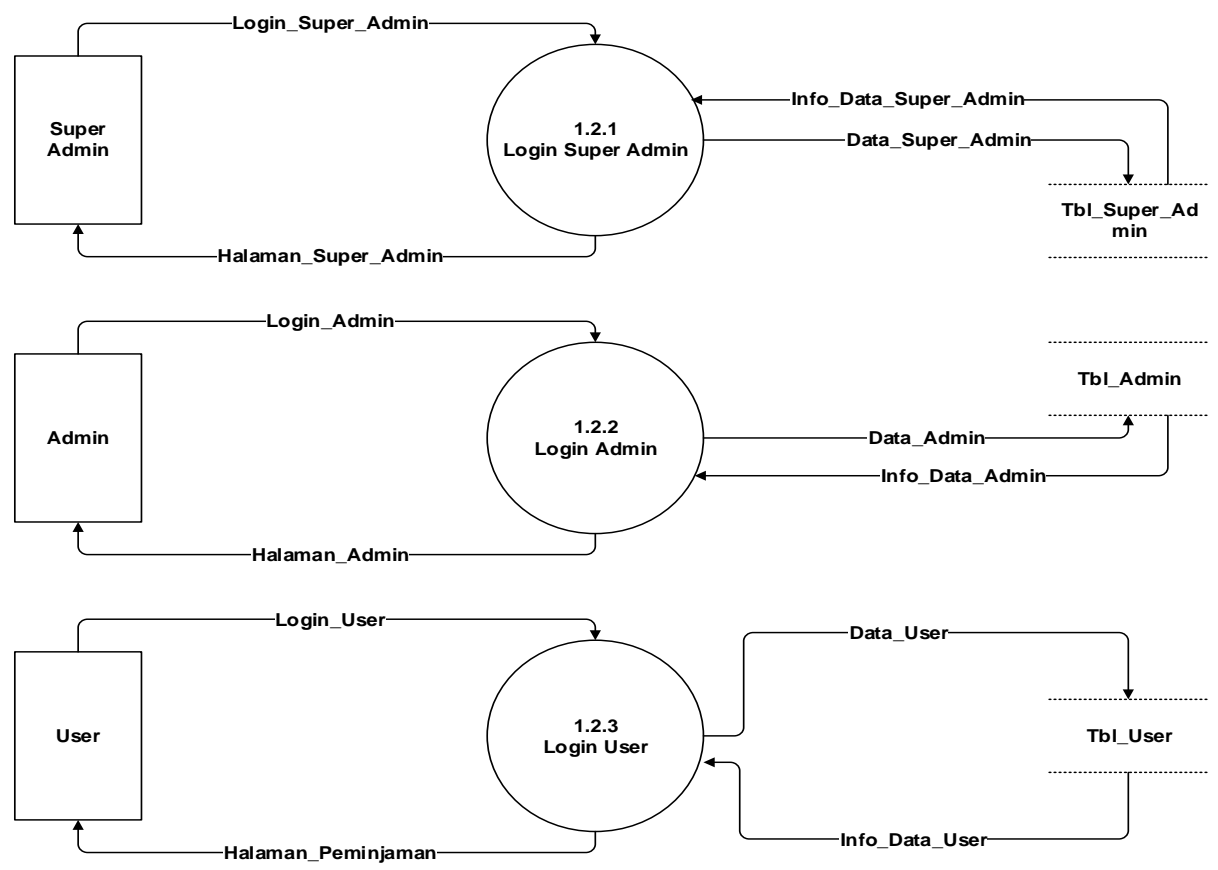

Gambar 8. Data Flow Diagram (DFD) level 1 Login 
Citec Journal, Vol. 3, No. 4, Agustus 2016 - Oktober 2016

\subsubsection{Data Flow Diagram (DFD) level 1 Peminjaman}

Gambar 9 merupakan Data Flow Diagram (DFD) level 1 Peminjaman. Dimana proses Peminjaman di pecah menjadi 3 (tiga) yaitu Pinjam, Konfirmasi dan Status.

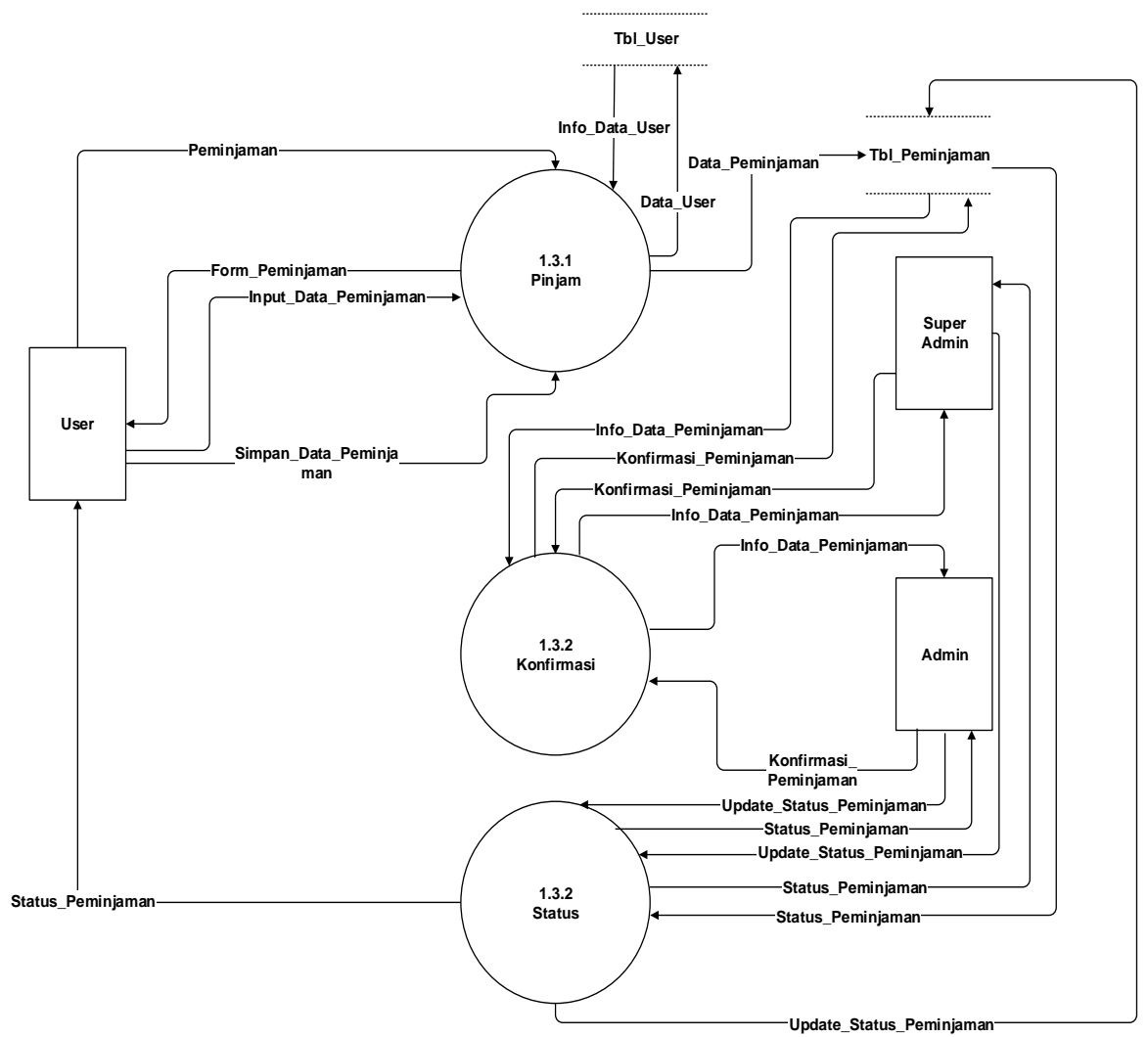

Gambar 9. Data Flow Diagram Level 1 Peminjaman 


\subsection{Entity Relationship Diagram (ERD)}

Entity Relationship Diagram (ERD) untuk penelitian ini ditunjukkan pada Gambar 10.

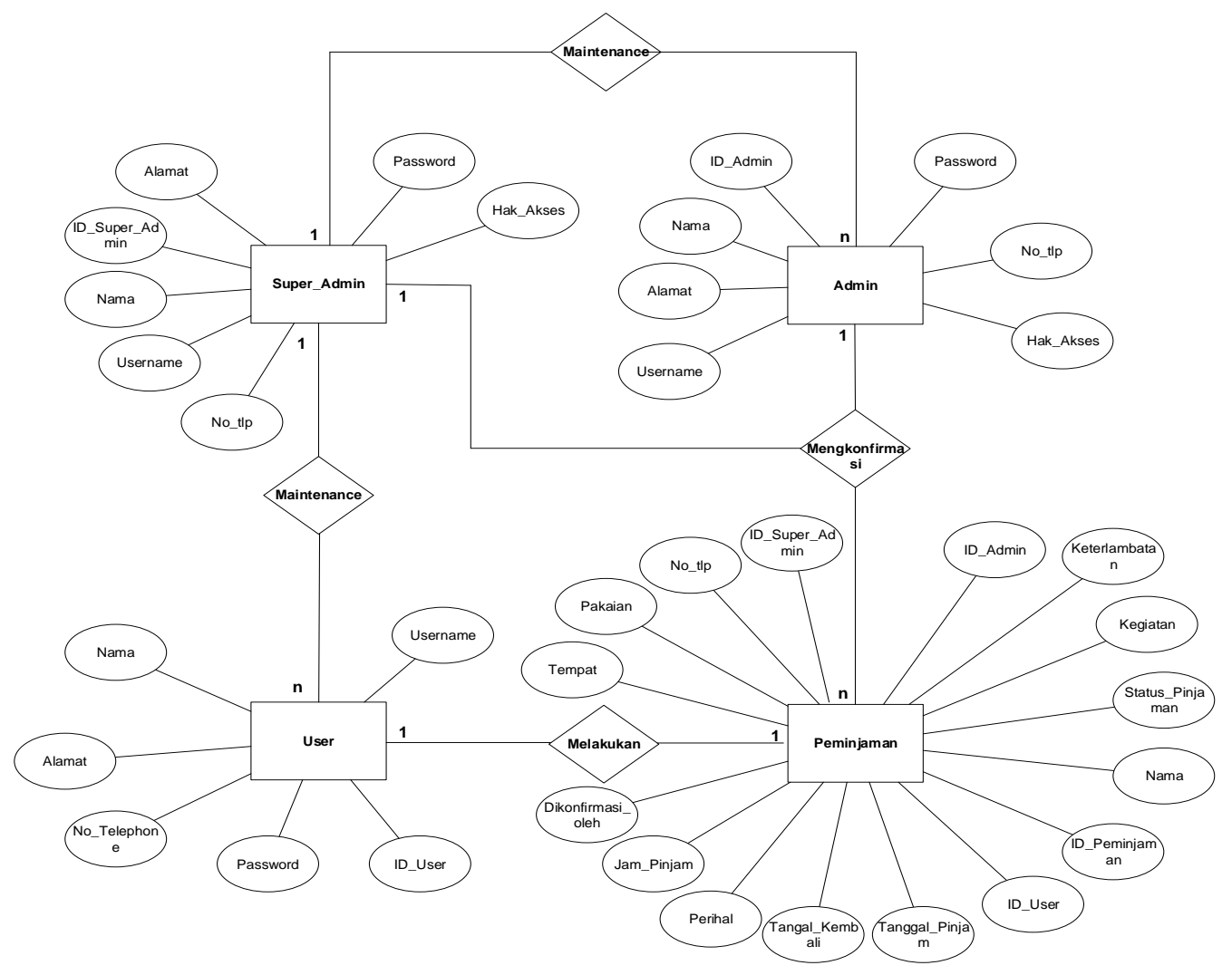

Gambar 10. Entity Relationship Diagram (ERD) 
Citec Journal, Vol. 3, No. 4, Agustus 2016 - Oktober 2016

\subsection{Relasi Database}

Gambar 11 menggambarkan hubungan antar tabel yang ada pada database sistem. Dari gambar diatas dapat dilihat bahwa database memiliki 4 buah tabel. Tabel-tabel tersebut antara lain Tbl_Super_Admin, Tbl_Admin, Tbl_User dan Tabel Peminjaman.

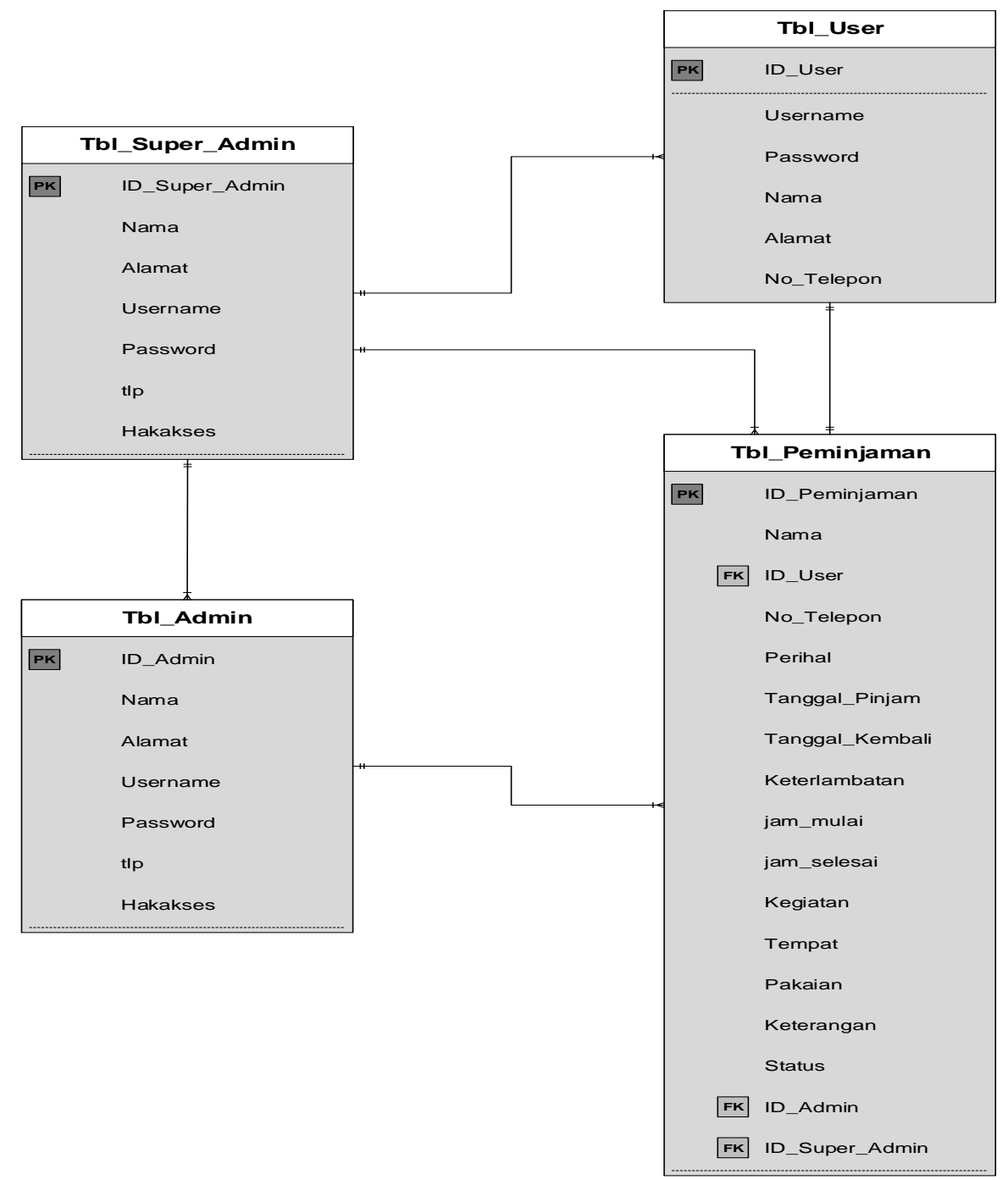

Gambar 11. Relasi Database

\subsection{Desain Antarmuka}

\subsubsection{Halaman Utama Admin}

Gambar 12 merupakan tampilan Desain Interfaces untuk Halaman Utama untuk Admin pada Website Peminjaman Sound System Kantor Camat Rendang. 


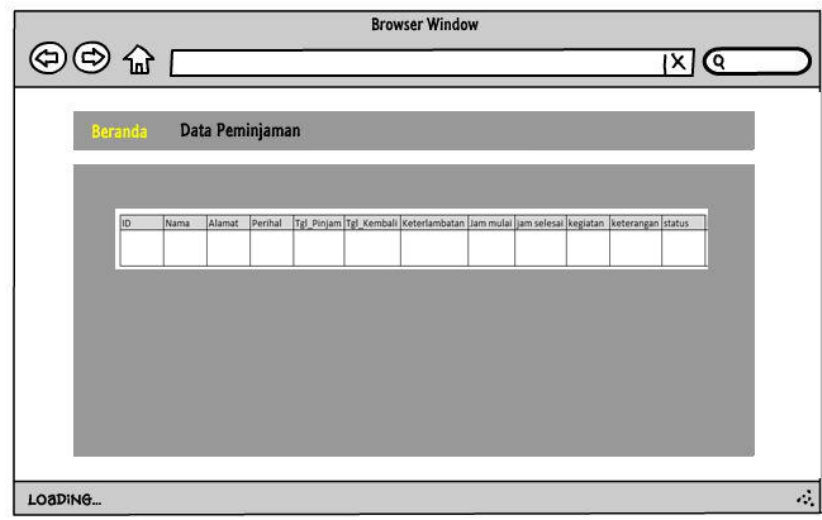

Gambar 12. Halaman Utama Admin

\subsubsection{Halaman Data Peminjaman Admin}

Gambar 13 merupakan tampilan Desain Interfaces untuk Halaman Data Peminjaman yang belum di konfirmasi oleh Admin pada Website Peminjaman Sound System Kantor Camat Rendang

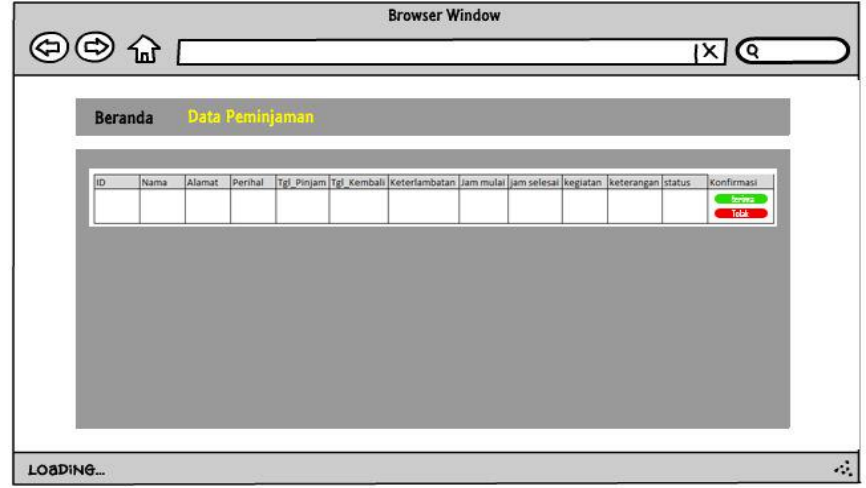

Gambar 13. Halaman Data Peminjaman Admin

\subsubsection{Halaman Utama User}

Gambar 14 merupakan tampilan Desain Interfaces untuk Halaman utama untuk User pada Website Peminjaman Sound System Kantor Camat Rendang.

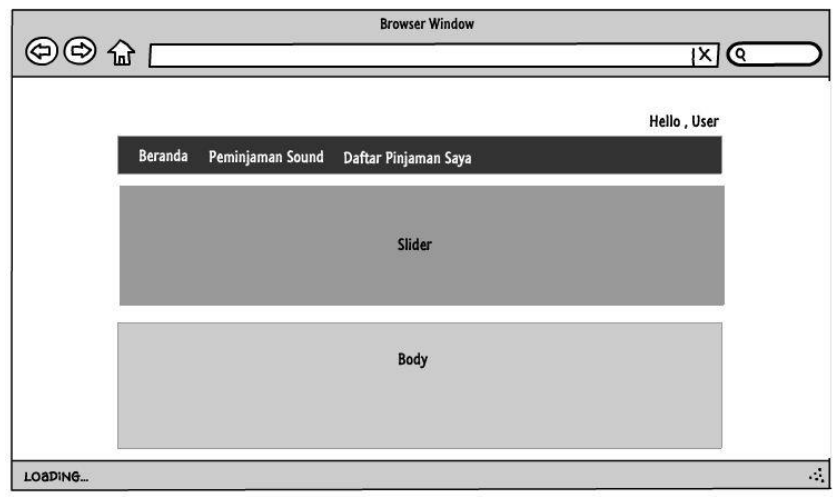

Gambar 14. Halaman Utama User 
Citec Journal, Vol. 3, No. 4, Agustus 2016 - Oktober 2016

\subsubsection{Halaman Peminjaman Sound User}

Gambar 15 merupakan tampilan Desain Interfaces untuk Halaman Form Peminjaman Sound untuk User pada Website Peminjaman Sound System Kantor Camat Rendang.

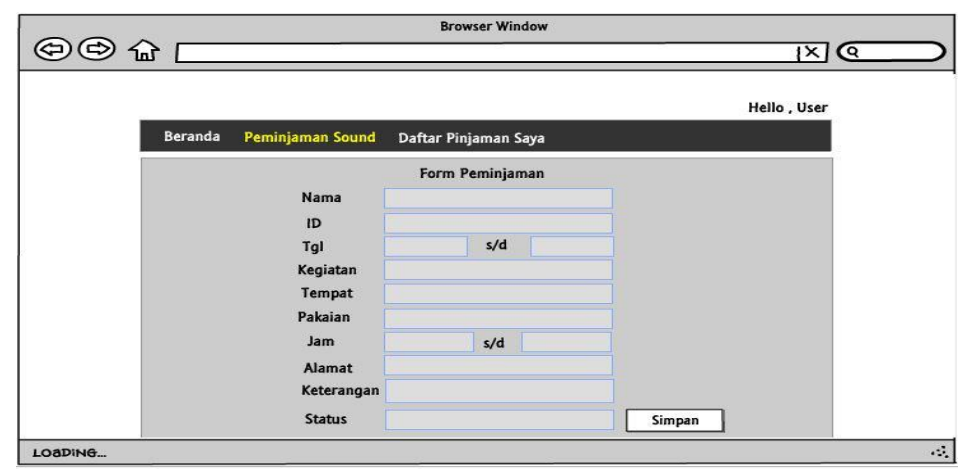

Gambar 15. Halaman Peminjaman Sound System User

\subsubsection{Halaman Daftar Pinjaman User}

Gambar 16 merupakan tampilan Desain Interfaces untuk Daftar peminjaman User pada Website Peminjaman Sound System Kantor Camat Rendang.

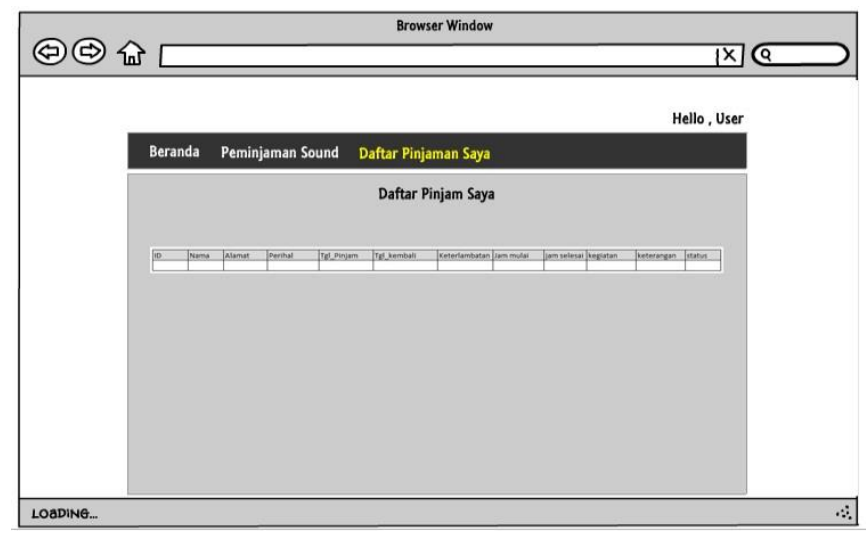

Gambar 16. Halaman Daftar Peminjaman User

\section{KESIMPULAN}

Berdasarkan penelitian yang dilakukan, maka diperoleh kesimpulan sebagai berikut:

1. Penelitian ini telah menghasilkan suatu rancangan system informasi peminjaman sound system berbasis web.

2. Rancangan system yang terdiri dari Data Flow Diagram (DFD), Entity Relationship Diagram (ERD), Relasi Database, Struktur Tabel dan Desain Interface.

3. Perancangan ini dapat membantu Developer dalam membangun system informasi peminjaman sound system pada Kantor Camat Rendang.

4. Aplikasi yang dirancang belum mengacu pada suatu platform tertentu, sehingga tampilan antarmuka (design interface) masih dapat dikembangkan lebih lanjut. 
5. SARAN

Beberapa hal yang dapat disarankan untuk menjadi bahan pertimbangan dalam penelitian selanjutnya, yaitu:

1. Agar penelitian ini dapat diimplementasikan menjadi system.

2. Mengingat perkembangan bahasa pemrograman dan development tools yang ada saat ini, maka sebaiknya dalam pengembangan aplikasi ini menggunakan bahasa pemrograman berorientasi objek.

3. Perlunya menambahkan lebih banyak atribut utama agar system dapat dipergunakan menjadi lebih baik dan mudah serta meningkatkan kwalitasnya.

\section{Ucapan Terima Kasih}

Peneliti ucapkan terimakasih kepada pihak STIKOM Bali yang telah membiayai penelitian ini sehingga penelitian ini dapat diselesaikan.

\section{DAFTAR PUSTAKA}

[1] Wahyono, T., 2004, Sistem Informasi (Konsep Dasar, Analisis Desain dan Implementasi), Graha Ilmu, Yogyakarta

[2] Peranginangin, K., 2006, Aplikasi Web dengan PHP dan MySQL, Penerbit Andi, Yogyakarta

[3] Agung, G., 2012, Buku Pintar HTML5 + CSS3 + DREAMWEAVER CS6, Elex Media Komputindo, Jakarta

[4] Kadir, A, 2009, Dasar Perancangan \& Implementasi Database Relasional, Penerbit Andi, Yogyakarta 